\title{
An unusual case of long standing vaginal foreign body removed with obstetric forceps
}

\author{
Padmalata, Naima Fathima*
}

Department of Obstetrics \& Gynaecology, SVS Medical College Hospital, Mahabubnagar, Telangana, India

Received: 11 February 2015

Accepted: 01 March 2015

\author{
*Correspondence: \\ Dr. Naima Fathima, \\ E-mail: naimaatmbnr@yahoo.com
}

Copyright: $\odot$ the author(s), publisher and licensee Medip Academy. This is an open-access article distributed under the terms of the Creative Commons Attribution Non-Commercial License, which permits unrestricted non-commercial use, distribution, and reproduction in any medium, provided the original work is properly cited.

\begin{abstract}
This is a case of retained foreign body in vagina for 10 years, a wood apple which was inserted to reduce uterine prolapse. It was retained without any symptoms for 10 years. The foreign body was removed using obstetric forceps after other methods were failed.
\end{abstract}

Keywords: Foreign body in vagina, Wood apple, Uterine prolapse

\section{INTRODUCTION}

Vaginal foreign bodies retained for long duration are uncommon in present day scenario. Irrespective of age, when a female presents with recurrent, foul smelling vaginal discharge, foreign body should be suspected. ${ }^{1}$ This case is reported as it is unusual to find foreign bodies like wood apple inserted in the vagina as a treatment of uterine prolapse, which was retained for 10 years without symptoms. The patient was from a rural back ground and it was a usual practice to insert objects such as wood apple to reduce prolapsed uterus. The foreign body was removed using obstetric forceps after other methods have failed.

\section{CASE REPORT}

A 65 years old woman, who is from a rural background presented to Gynaecology OPD with recurrent offensive discharge $\mathrm{p} / \mathrm{v}$ for the last 2 years. She visited a local practitioner and received symptomatic treatment about which no documents were available. No history of bleeding $\mathrm{p} / \mathrm{v}$, no urinary or bowel symptoms, no abdominal pain, nausea, vomiting, fever, loss of weight and appetite was reduced recently. She was not sexually active. She attained menopause 15 years ago. On further questioning she revealed that she developed mass per vagina 12 years ago for which she visited a local quack and something was inserted into the vagina to reduce the mass. There was no significant past medical and surgical history. She was para 4, all deliveries were full term spontaneous vaginal deliveries at home conducted by a local untrained dai.

General examination was unremarkable. She was afebrile, other vital data were normal. Per abdominal examination was unremarkable. Local examination revealed external genitalia to be atrophic, foul smelling, profuse blood stained watery discharge was seen at introitus. On retracting the labia, a black, round mass resembling a foetal head was noted in the vagina. Sim's speculum couldn't be inserted in to the vagina due to the obstruction by the foreign body. She was admitted for removal of foreign body under anaesthesia. Routine blood investigations were within normal limits. A swab of the vaginal discharge grew Klebsiella sp. USG of the pelvis showed uterus of $6.8,2.1 \mathrm{~cm}$ with endometrial thickness $3 \mathrm{~mm}$ and indistinct cervico vaginal junction. A well-defined hyperechoic focus noted within vagina with an impression of foreign body. 
After commencing antibiotics she was taken to OT for removal of foreign body under anaesthesia. Under regional anaesthesia attempt was made to remove the foreign body manually which was unsuccessful due to lack of space in the vagina. So perineotomy was done and another attempt was made to remove the foreign body manually which was failed. Wrigley's obstetric outlet forceps was then used to grasp the foreign body and it was removed without much difficulty. It was found to be a spherical, black, stony hard wood apple. Vagina was explored thoroughly for ulcerations, growth, granulation tissue and nothing was found. Generalized ooze from the raw area was controlled with pressure. Cervix was small and atrophic at the vault. On bimanual examination uterus was found to be small in size, and fornices were free. After removing the foreign body there was no descent of the uterus and cervix even with traction. Postoperative period was uneventful and the patient was discharged after completing the course of antibiotics.

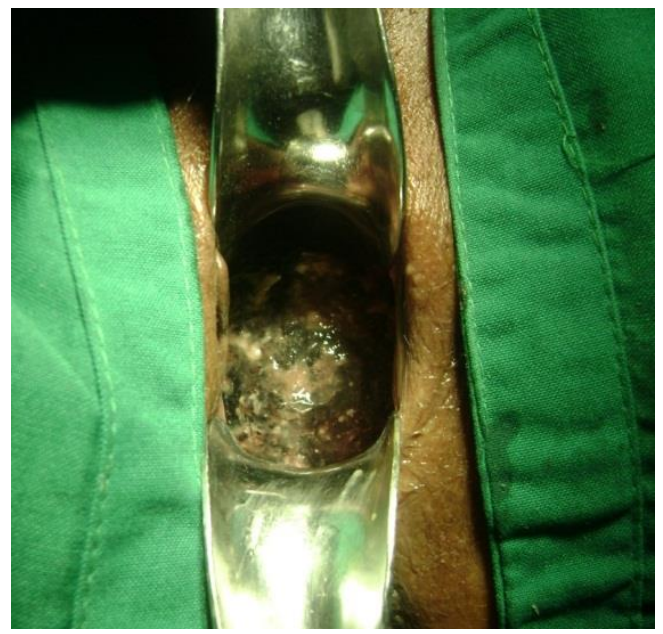

Figure 1: Foreign body seen in vagina.

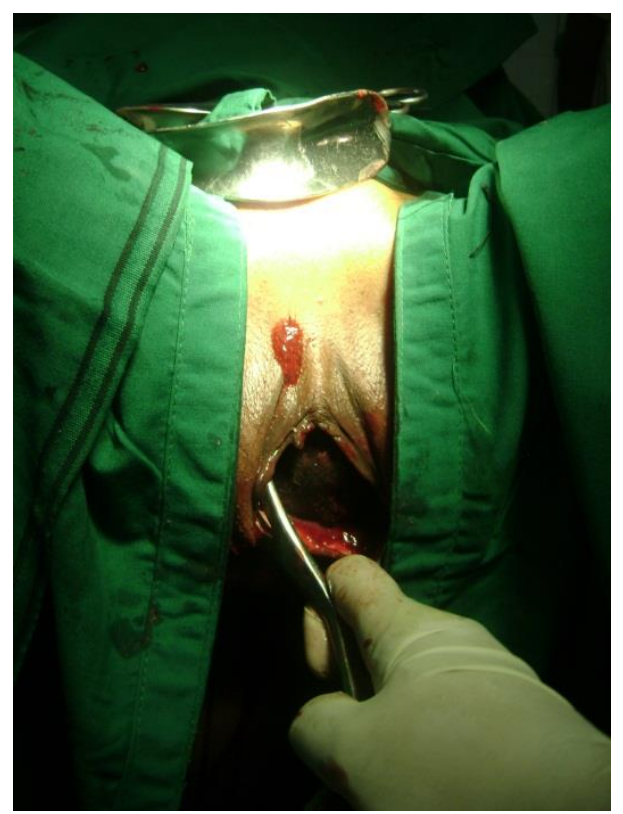

Figure 2: Foreign body held with forceps.

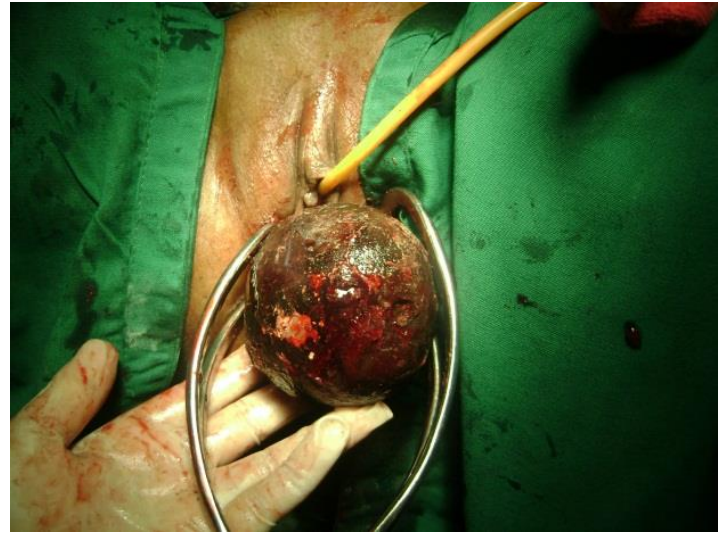

Figure 3: Foreign body extracted with forceps.

\section{DISCUSSION}

Vaginal foreign bodies can be symptomatic or asymptomatic. Various objects like contraceptive devices (diaphragms, vaginal rings, condoms), tampons, pessaries, suppositories, vibrators, sex toys have been described. $^{2,5}$ When foreign bodies are present for long duration, they can lead to various problems, infection, pelvic peritonitis and abscess, vesico vaginal, recto vaginal fistula, impaction due to scarring and fibrosis. ${ }^{1}$ In the present case a wood apple was inserted to reduce the prolapsed uterus. ${ }^{4}$ This mode of treatment was first described by Soranus who first used a woollen tampon dipped in vinegar to reduce the prolapse. ${ }^{7}$ Wood apple is indigenous in south East Asian countries and few decades ago it was commonly used to treat uterine prolapse in rural parts of India. However this practice is obsolete with the advent of safe anaesthetic and surgical techniques. Now a day a wood apple left in the vagina of such long duration (10 years) is very rarely found. When such foreign bodies are found they should be removed either manually or after holding with instruments. There are very few case reports in the literature where obstetric forceps and a soft vaccum cup were used to extract the foreign body successfully where other methods have failed. $^{3,6}$ In our case we had to resort to using the obstetric forceps which was successful. The wood apple would have caused fibrosis which had prevented the further development of prolapse of uterus after the removal of the object.

\section{Funding: No funding sources \\ Conflict of interest: None declared \\ Ethical approval: Not required}

\section{REFERENCES}

1. Brig S. Chopra, Y. Singh, N. Magon. A case of intravaginal foreign body. Med J Armed Forces India. 2010;66:266-8.

2. Dasari P, Sagili H. Incarcerated foreign body in the vagina- a metal bangle used as a pessary. BMJ Case Rep. 2012;2012:pii: bcr0120125596. 
3. Emge KR. Vaginal foreign body extraction by forceps. Am J Obstet Gynaecol. 1993;169:1891-2.

4. B. Venkateswara Rao. A rare presentation of a foreign body in vagina (wood apple). J Evol Med Dent Sci. 2014 Mar;3(13):3324-6.

5. Nwosu EC, Rao S, Igweike C, Hamed H. Foreign objects of long duration in the adult vagina. J Obstet Gynaecol. 2005;25(7):737-9.

6. Pelosi MA, Giblin S, Pelosi MA 3rd. Vaginal foreign body extraction by obstetric soft vacuum cup: an alternative to forceps. Am J Obstet Gynecol. 1993 Jun;168(6 Pt 1):1891-2.

7. Keith T. Downing. Uterine prolapse: from antiquity to today. Obstet Gynecol Int. 2012;2012:649459.

DOI: $10.5455 / 2320-1770 . i j r \operatorname{cog} 20150447$

Cite this article as: Padmalata, Fathima N. An unusual case of long standing vaginal foreign body removed with obstetric forceps. Int J Reprod Contracept Obstet Gynecol 2015;4:502-4. 